\title{
Morphological Effects of Heat Stress on Cattle Kidney
}

\author{
Murat Sırrı Akosman ${ }^{1}$ İsmail Türkmenoğlư ${ }^{1}$ Aysun Çevik Demirkan ${ }^{1}$ Vural Özdemir ${ }^{1}$ \\ Mehmet Aydın Akalan ${ }^{1}$ \\ ${ }^{1}$ Department of Anatomy, Faculty of Veterinary Medicine, University \\ of Afyon Kocatepe, Afyonkarahisar, Turkey \\ J Morphol Sci 2018;35:122-124. \\ Address for correspondence Murat Sırrı Akosman, Associate \\ Professor, Department of Anatomy, Faculty of Veterinary Medicine, \\ ANS Campus, University of Afyon Kocatepe, Afyonkarahisar, Turkey \\ (e-mail: akosmans@aku.edu.tr).
}

\begin{abstract}
Introduction Cattle kidney is an interesting organ because of its individual morphological structure and the mobility of the left kidney. The effects of heat stress on animal yield have been previously researched. However, no data could be obtained during the literature research about the effects of heat stress on the morphological structure of cattle kidneys. Materials and Methods In the present study, morphometric measurements were performed on the left and right kidneys of male and female Holstein cattle. The kidney samples were collected in the summer and winter seasons to assess the effects of heat stress. A scale, water overflow, and a Mitutoyo CDN-P20PMX caliper (Mitutoyo Corporation,

Keywords

- cattle

- heat stress

- kidney

- morphometry

- stereology Kanagawa, Japan) were used to obtain the morphological structural data of the total kidney, and stereological sampling methods with microscopy were performed to investigate the glomerulus density per unit area and the diameter of the glomerulus.

Results Morphological changes on the kidneys were observed after the measurements. Conclusion It can be said that heat stress may cause morphologic changes on cattle kidneys.
\end{abstract}

\section{Introduction}

The bovine kidney is lobulated due to its multilobar structure, ${ }^{1}$ and the left kidney is mobile in order to avoid the pressure from the rumen when it is full. ${ }^{1}$ The functional urine filtration unit of the kidney is the nephron, ${ }^{1}$ and all nephrons are placed in the Bowman capsule, in the cortical region. ${ }^{1}$ The primary function of the kidney is to keep the body fluid ingredients within the physiological limits. The morphometric features of the kidney may be useful for the diagnosis of diseases. ${ }^{2,3}$ Changes in some of the morphometric parameters may indicate the health status of the organs. ${ }^{2,3}$ For example, the total volume of the kidney is directly related to its functional reserve, and its weight is related to chemical changes. ${ }^{4}$

In the present study, morphometric measurements were performed on the left and right kidneys of both male and female Holstein cattle. The kidney samples were collected in the summer and winter seasons to assess the effects of heat stress on them. A scale, water overflow, and a Mitutoyo CDN-P20PMX caliper (Mitutoyo Corporation, Kanagawa, Japan) were used to obtain the morphological dimensions of

received

August 10, 2017

accepted

August 3, 2018

published online

August 31, 2018

10.1055/s-0038-1669431. ISSN 2177-0298. the total kidney, and the stereological sampling methods with microscopy were performed to investigate the glomerulus density per unit area and the diameter of the glomerulus.

\section{Materials and Methods}

In the summer and winter seasons, the left and right kidneys of 40 Holstein cattle (10 male and 10 female for the summer season. and 10 male and 10 female for the winter season) were collected from the slaughterhouse. Immediately after the slaughtering, all kidneys were weighted using a Kern scale (Kern, Balingen, Germany). The widths of the cranial pole, of the middle region, and of the caudal pole, as well as the total length, were measured with a Mitutoyo CDN-P20PMX caliper. The total kidney volume was estimated using a graded cylinder according to the principle of Archimedes.

After all the morphometric measurements, the kidneys were sliced into equal intervals according to the stereological systematic uniform sampling procedure. ${ }^{5-7}$ The chosen slabs were fixed in neutral buffered $10 \%$ formalin, sliced in a

Copyright $\odot 2018$ by Thieme Revinter

Publicações Ltda, Rio de Janeiro, Brazil

License terms

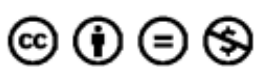




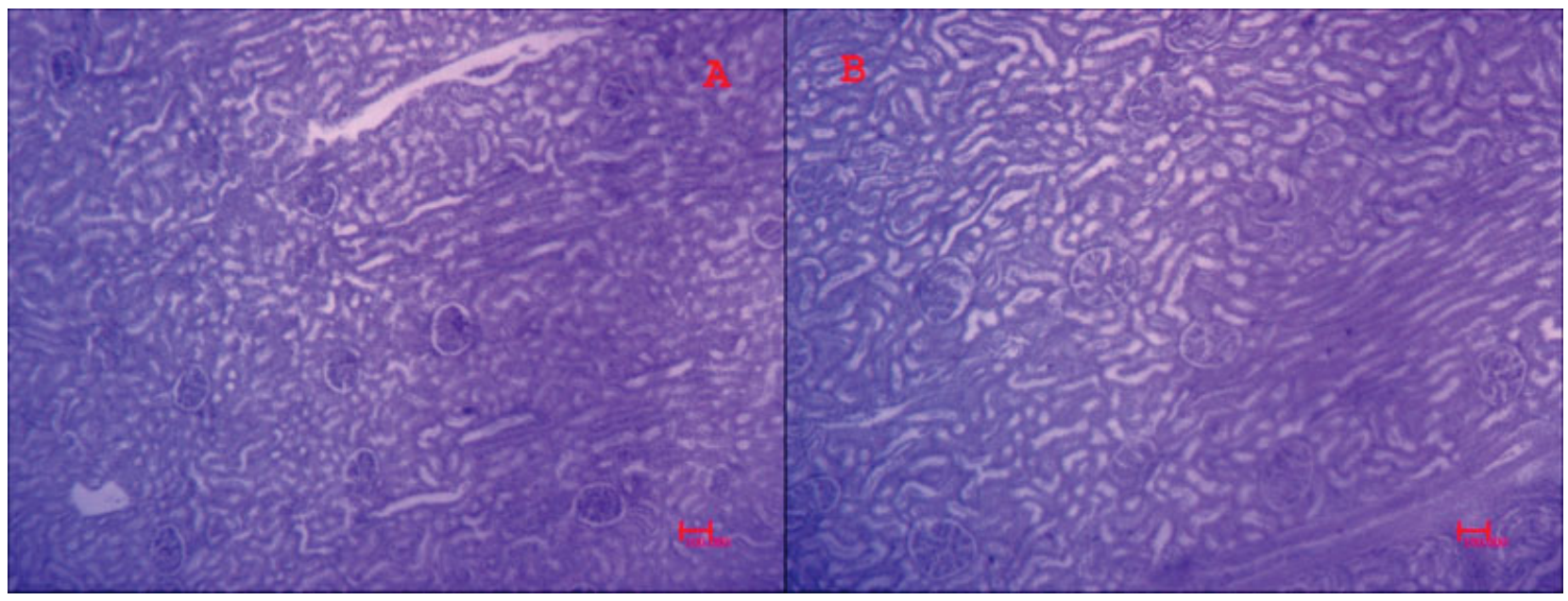

Fig. 1 A glomerular view from the (A) small and (B) big kidneys.

thickness of $5 \mu \mathrm{m}$, and stained with hematoxylin. The number of glomerulus per unit area and the diameter of the glomerulus were calculated with an Olympus BH-2 (Lang MS316) motorized staged light microscope (Olympus Corporation, Tokyo, Japan) attached to a computer running the MShot Image Analysis System 1.3.10 software (Micro-shot Technology Limited, Guangzhou, China). For the number estimation, the motorized stage moved $2 \mathrm{~mm}$ along equal step lengths and the glomeruli were counted, falling into the $917,534 \mu \mathrm{m}^{2}$ long frame in 10 consecutive areas (-Fig. $\mathbf{1}$ ).

The independent sampling $t$-test was used for the statistical evaluations.

\section{Results}

In the summer season group, the length of the left kidneys was statistically shorter and the width of the caudal pole was wider than the right kidney in the male Holstein cattle $(p<0.05)$.The cranial pole width of the female Holstein cattle left kidneys was smaller and its caudal pole was statistically longer than those of the right kidneys ( $p<0.05)$ ( - Fig. 2 ). In the winter groups, no statistical differences were detected in the left and right kidneys of male and female cattle.

When the average of both kidneys was calculated in the summer season, the volume and the length of the male Holstein cattle kidneys and only the length of the female Holstein cattle kidneys were statistically longer than the measurement obtained during the winter season $(p<0.05)$.

No differences were detected in the male Holstein cattle kidneys when the averages of the left kidneys in the summer season were compared with the averages of the left kidneys in the winter season. However, in the female Holstein cattle kidneys, the kidney length was longer, and the width of the cranial pole was narrower in the summer season $(p<0.05)$. Besides, the length of the right kidney of the male Holstein cattle was statistically longer in the summer season $(p<0.05)$, and no differences were detected in the female Holstein cattle kidneys.

Finally, the weight, length, volume, width and glomerular diameter of female Holstein cattle kidneys in both groups were statistically larger compared with the kidneys of the male Holstein cattle kidneys ( $p<0.05$ ).

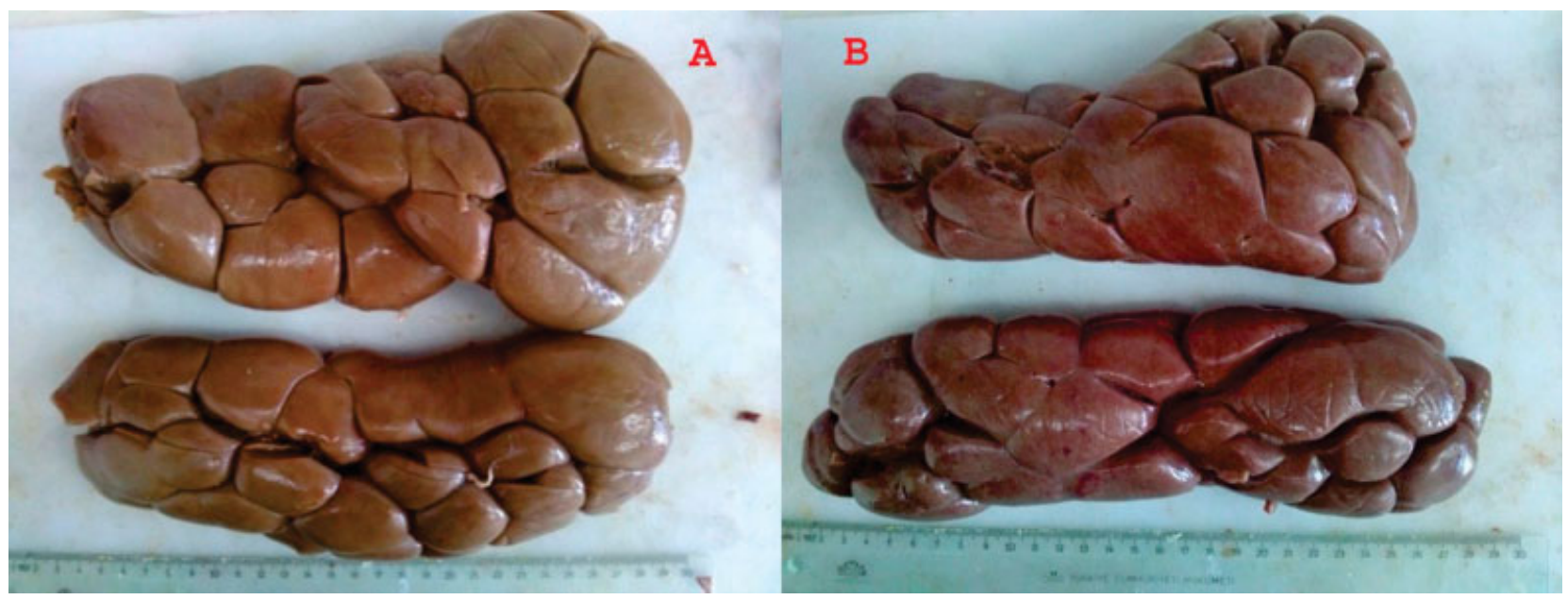

Fig. 2 Kidneys of the female (A) and male (B) Holstein cattle. The left kidneys are on the upside and the right kidneys are on the downside. 


\section{Discussion}

The milk yield is affected by the heat in the summer season. The heat has negative effects on the milk production. ${ }^{8}$ The heat stress also affects the glomerular and tubular functions and urine concentrations in the kidneys. ${ }^{9,10}$ Cincovic et $\mathrm{al}^{9}$ found that the warming air decreases the milk production, and it affects negatively the milk quality and increases the amount of urea and bilirubin in the milk. All these studies tried to estimate the heat effects on different body conditions, and no morphological studies were found in the literature, except in the report by Pitesky et $\mathrm{al}^{11}$, who stated that the environmental heat stress decreases the number of functional glomerulus in dogs. However, in the present study, depending on the season, no change was detected in the number and in the diameter of the glomerulus.

In the present study, it was observed that the front width of the left kidney decreases and that the back width increases in the summer season. Therefore, the front region of the left kidney gets thinner and the back region of the left kidney gets thicker. The alteration in the structure of the left kidney may be caused by the stomach rumen of the Holstein cattle. One must remember that the left kidney is mobile because of the protection against the pressure caused by the fullness of the rumen.

According to the comparison of the mean kidney parameters in the summer and winter seasons, the length and the volume of the male Holstein cattle kidneys were much longer and larger, respectively; and the length of the female Holstein cattle kidneys was much longer in the summer season than in the winter season. The right kidney of the male Holstein cattle was smaller in the winter season than in the summer season. Besides, in the female Holstein cattle, in the summer season, the kidneys length was getting bigger, while in the winter season the front widths were getting bigger. No statistically significant changes were observed in the glomerulus density per unit area and in the diameter of the glomerulus when the seasons were compared.

\section{Conclusion}

In the present study, the morphological effects of the seasonal heat changes were observed on the Holstein cattle kidneys.

\section{Acknowledgments}

The present study was funded by the Scientific Research Projects Centre of the Afyon Kocatepe University (13.VF.06).

\section{References}

1 König HE, Liebich HG. Veterinary anatomy of domestic mammals textbook and colour atlas. Germany: AZ Druck und Datentechnik GmbH; 2004

2 Bailey SA, Zidell RH, Perry RW. Relationships between organ weight and body/brain weight in the rat: what is the best analytical endpoint? Toxicol Pathol 2004;32(04):448-466

3 Michael B, Yano B, Sellers RS, et al. Evaluation of organ weights for rodent and non-rodent toxicity studies: a review of regulatory guidelines and a survey of current practices. Toxicol Pathol 2007; 35(05):742-750

4 Adibi A, Naini AE, Salehi H, Matinpour M. Renal cortical thickness in adults with normal renal function measured by ultrasonography. Iran J Radiol 2008;5(03):163-166

5 Gundersen HJ, Bendtsen TF, Korbo L, et al. Some new, simple and efficient stereological methods and their use in pathological research and diagnosis. APMIS 1988;96(05):379-394

6 Gundersen HJ, Bagger P, Bendtsen TF, et al. The new stereological tools: disector, fractionator, nucleator and point sampled intercepts and their use in pathological research and diagnosis. APMIS 1988;96(10):857-881

7 Gundersen HJG, Jensen EBV, Kiêu K, Nielsen J. The efficiency of systematic sampling in stereology-reconsidered. J Microsc 1999; 193(Pt 3):199-211

8 Bernabucci U, Lacerta N, Ronchi B, Nardone A. Effects of the hot season on milk protein fractions in holstein cows. Anim Res 2002; 51:25-33

9 Cincovic MR, Belic B, Toholj B, et al. Metabolic acclimation to heat stress in farm housed Holstein cows with different body condition scores. Afr J Biotechnol 2011;10(50):10293-10303

10 McAllan BM, Roberts JR, O'Shea T. Seasonal changes in glomerular filtration rate in Antechinus stuartii (Marsupialia: Dasyuridae). J Comp Physiol B 1998;168(01):41-49

11 Pitesky I, Last JH. Effects of seasonal heat stress on glomerular and tubular functions in the dog. Am J Physiol 1951;164(02):497-501 